\title{
PESSOAS COM DEFICIÊNCIA NO BRASIL: ASPECTOS CULTURAIS, HISTÓRICOS E CONSTITUCIONAIS DE SUA TRAJETÓRIA
}

\author{
Lucilene Quintiliano Alves ${ }^{1}$
}

RESUMO: $\mathrm{O}$ artigo aborda aspectos relevantes vinculados ao percurso das pessoas com deficiência no país com um enfoque maior nos anos de 1991, 2000 e 2010, o intuito deste trabalho é prover um estudo mais aprofundado sobre as perspectivas mais pertinentes ao tema, dando ênfase tanto a acessibilidade que desponta como um meio eficaz para a solução do embate entre a sociedade e as pessoas com necessidades especiais, como também a educação inclusiva a qual promove distintos ganhos a população com e sem deficiência.

Para obter os resultados previstos a metodologia utilizada apoia-se no método descritivocrítico inicialmente, sendo feito uma investigação bibliográfica, a observação da doutrina e normas brasileiras em relação ao assunto em foco.

Palavras-chaves: Pessoas com deficiência. Discriminação. Acessibilidade. Educação Inclusiva.

ABSTRACT: The article discusses relevant aspects related to the course of disabled people in the country with a greater focus in the years I99I, 2000 and 20I0, the purpose of this work is to provide a more in depth study on the most pertinent perspectives to the theme, emphasizing both the accessibility which emerges as an effective means for solving the clash between society and people with special needs, as well as inclusive education which promotes distinct gains for the disabled and non-disabled population. In order to obtain the expected results, the methodology used is based on the descriptive-critical method initially, being carried out a bibliographical investigation the observation of Brazilian doctrine and norms in relation to the subject in focus.

Keywords: People with disabilities. Discrimination. Accessibility. Inclusive Education.

\section{INTRODUÇÃO}

O presente artigo versa sobre o tema "Pessoas com deficiência no Brasil: aspectos culturais, históricos e constitucionais de sua trajetória.” Hodiernamente no Brasil, segundo o censo demográfico de 2010 do Instituto Brasileiro de Geografia e Estatística (IBGE) cerca de $24 \%$ da população brasileira possui algum tipo de deficiência, o que representa em torno

\footnotetext{
${ }^{1}$ Acadêmica do curso de Bacharelado em Direito da Universidade Estadual de Feira de Santana, BA, Brasil. Email: cyleneroo@hotmail.com.
} 
de 45 milhões de pessoas. Ademais, o Decreto Lei $\mathrm{n}^{\mathrm{O}} 298 \backslash 99$ em seu artigo $4^{\underline{0}}$ traz em seu bojo sistematicamente cinco tipos de deficiências, a saber, física, auditiva, visual, mental e múltipla, é uma tentativa de elencar quais tipos de deficiência existem no país, embora não exista um rol taxativo da mesma, permitindo assim que outros regulamentos versem sobre tal classificação.

Segundo o mesmo, a deficiência física compreende a alteração completa ou parcial de um ou mais segmentos do corpo humano, por consequência provocando comprometimento da função física, esta pode se apresentar, por exemplo, na forma de paraplegia, ausência de membros, paralisia cerebral entre outras. $\mathrm{O}$ dispositivo cita também a deficiência auditiva caracterizada como a perda bilateral, parcial ou total de quarenta e um decibéis $(\mathrm{dB})$ ou mais aferida por audiograma nas frequências de $500 \mathrm{HZ}, \mathrm{I} .000 \mathrm{HZ}, 2.000 \mathrm{~Hz}$ e $3.000 \mathrm{~Hz}$.

Por sua vez a deficiência visual é classificada como o comprometimento da capacidade visual de um ou ambos os olhos seja a perda parcial ou total. Trata também da deficiência mental, sendo posta como o funcionamento intelectual significamente inferior à média constada antes dos dezoito anos, a mesma pode vir acompanhada de limitações no campo da comunicação, habilidades sociais, cuidado pessoal entre outras. Por fim cita a deficiência múltipla onde existe associação de duas ou mais deficiências.

Além disso, a palavra deficiência, segundo o preâmbulo da Convenção da Organização das Nações Unidas sobre os Direitos das Pessoas com Deficiência adotada no Brasil através do Decreto Legislativo nํㅗㅇㅣ de 2008 e o Decreto n- 6.949 de 2009, é um termo que está em evolução, ainda de acordo com a mesma ela é resultado da relação entre as pessoas com deficiência e os obstáculos comportamentais, estruturais e sociais, os quais dificultam sua participação plena e eficaz na sociedade de forma igualitária, assim deste ponto de vista a deficiência é algo externo resultante do vínculo entre sociedade e a pessoa com necessidades especiais.

Outro termo que esteve em evolução ao longo do tempo é justamente a palavra cultura, a mesma pode ser concebida a partir de um primeiro momento pela definição de Edward Burnett Tylor que estabelece uma concepção etnológica da mesma em I87ı, o qual diz que "tomando em seu amplo sentido etnográfico (cultura) é este todo complexo que inclui conhecimento, crenças, arte, moral, leis, costumes ou qualquer outra capacidade ou 
hábitos adquiridos pelo homem como membro de uma sociedade.” (apud LARAIA, 2006, p.25)

Contemplando esse conceito percebe-se que a cultura não é algo inato do homem, mas sim, aprendido pelos indivíduos de cada sociedade. Dessa forma vislumbrando a realidade brasileira a partir do mesmo, pode-se chegar à origem da discriminação contra pessoas com deficiência, pois analisando a história brasileira ao longo dos séculos verifica-se uma propensão à exclusão, segregação e rejeição destes brasileiros, a qual vem sendo assimilada e repassada pelas gerações até os dias atuais. Com o intuito de romper com essa tendência social da discriminação, despontam leis que amparam tais pessoas, rompendo com a velha associação entre deficiência e incapacidade, demostrando assim que estes, são capazes de estudar, trabalhar, construir famílias, enfim são capacitados a chegarem até onde suas limitações físicas permitem. O estudo do tema torna-se relevante em um momento histórico do país que as minorias lutam para adquirir resguardo legal, e assim superando as barreiras impostas pela sociedade.

\section{INFLUÊNCIA CULTURAL NA NEGAÇÃO DA DIVERSIDADE HUMANA PELA SOCIEDADE BRASILEIRA}

Através da análise dos pensamentos de Thompson (1995), sociólogo contemporâneo, pode-se aprofundar o estudo em torno do conceito de cultura, a partir dos mesmos se depreende a existência de quatro formas diferentes de definir tal termo, essas apresentam uma evolução da noção dessa palavra, as mesmas podem ser identificadas como, clássica, a qual faz nítida referência aos séculos XVIII e XIX, onde a noção de cultura era associada ao avanço intelectual e também podia ser encarada como sinônimo de civilização, a segunda concepção é nominada como descritiva a qual reúne um arcabouço composto por valores, costumes, crenças de uma sociedade, a terceira e a quarta são conhecidas como simbólica e estrutural respectivamente, a visão simbólica encara os fenômenos culturais por intermédio dos seus significados, mediante essa concepção o autor formula outra noção de cultura de forma a englobar todos os contextos gerais onde os fenômenos sociais estão estabelecidos, pontuando assim que "os fenômenos culturais podem ser entendidos como formas simbólicas em contextos estruturados; e a análise cultural pode ser pensada como o estudo da constituição significativa e da contextualização social das formas simbólicas.” (Thompson, 1995, p.166) 
Dessa maneira, se pode inferir que estereótipos, padrões de beleza, estigmas e rótulos que são formulados pela sociedade ao longo do tempo, constituem símbolos sociais, estes associados aos comportamentos de exclusão e segregação em quadros estruturados permitem o surgimento da discriminação. Por conseguinte pessoas que destoam dos modelos corporais impostos pela sociedade, a qual duramente dita parâmetros de perfeição exorbitantes, são alvos contínuos de marginalização, além disso, as observações da diversidade humana feitas durante os anos na maioria das vezes promovem uma ênfase nos aspectos considerados como negativos das outras pessoas, a uma repulsa aos olhos da população brasileira do que é diferente, e esse comportamento sistematizado como citado anteriormente, é uma construção cultural, historicamente um dos grupos que se encontram nessa situação são as pessoas com deficiência. Em um primeiro momento o contato com pessoas com deficiência causa um ligeiro ou perpetuo estranhamento, pois como na sociedade o que prevalece como perfeito é o corpo saudável, tais pessoas traz à tona uma porção da heterogeneidade social que é negada e associada à fragilidade humana, essas medidas culturais acarretam consequências negativas a estas pessoas a principal delas é inacessibilidade. (SILVA, 2006, p.426)

\section{BREVE HISTÓRICO DO PERCURSO DAS PESSOAS COM DEFICIÊNCIA NO BRASIL}

A trajetória das pessoas com deficiência no país é árdua, revestida de maus tratos, abandono e impunidade, por falta de relatos e documentos oficiais a história destes nos primeiros séculos do Brasil é desprezada. Pode-se traçar uma linha histórica datada a partir do século XVI, século esse marcado tanto pela chegada dos europeus no solo brasileiro, como pelo choque cultural entre as culturas europeia e indígena. Os índios brasileiros no período pré-colonial viviam divididos em suas tribos, cada qual com suas crenças, rituais religiosos, linguagem, modo de trabalho, e sua forma de relação com a natureza. (FIGUEIRA, 20I8, p.I4-15)

Mas, algo havia em comum entre elas, segundo Figueira (2018, p.16) era possível encontrar incidência de exclusão dos índios brasileiros com deficiência, como pode ser constatado através de relatos de antropólogos e historiadores. Segundo o autor no ato do nascimento quando uma criança era detectada com deformidades físicas, seu futuro era imediatamente revestido de obscuridade, pois essa inocente criança, seria abandonada nas 
florestas, lançadas das montanhas ou até mesmo ser sacrificada impiedosamente em rituais religiosos, isso acontecia devido ao fato de que esses bebês eram considerados maldição para sua tribo. Infelizmente nos primórdios da história brasileira já era possível vislumbrar o conceito de "inferioridade", visto que aqueles índios eram encarados como futuros maus guerreiros, caçadores, sendo indignos de uma família. Tal visão predominava de acordo com Figueira (2018, p.23) pela presença de um tripé segregativo, a saber, preconceito, estereotipo e estigma.

Após esse período da história do Brasil, ocorre à colonização no ano de 1530, em seguida sucede o ciclo do açúcar, cuja mão de obra utilizada inicialmente era indígena, com o fracasso desse modelo, por distintos motivos, os portugueses optaram pelo emprego dos escravos africanos, padrão que perdurou até o fim do período imperial. Em 1559 deu-se início ao tráfico negreiro, a dor, o medo e a aflição daqueles africanos, disputavam o espaço com as frequentes preocupações do recomeço em uma terra estranha, as embarcações padeciam de péssimas condições higiênicas e estruturais, por conta disto inúmeros destes faleceram, ou ainda conseguiam chegar com vida, mas com sua saúde debilitada, pois além desses motivos expostos faltavam água e comida, em solo brasileiro somente os mais saudáveis seriam comercializados. (FIGUEIRA 2018, p.50)

Os africanos saudáveis eram sujeitos a trabalhos excessivos, sendo superexplorados pelos senhores de engenho, e inclusive quando cometiam alguma falta tinham que suportar a agonia de castigos físicos aterrorizantes incluindo mutilações, essas atrocidades estão registradas em documentos oficiais ${ }^{2}$. $\mathrm{O}$ destino desses africanos que por castigos físicos exorbitantes ou desastre nos engenhos, contraiam deformidades físicas, não era tão diferente dos índios de tempos atrás, em virtude de que esses escravos eram enjeitados pelos seus senhores, passando a ocupar os mais baixos escalões da sociedade, e ao mesmo tempo sentindo de perto o desespero por estar em uma terra estranha, sendo discriminado pela sociedade, isso predominou até o século XIX. (FIGUEIRA, 2018, p.63-64)

No decorrer dos séculos XX e XXI o avanço da medicina provocou o aumento da preocupação em relação às pessoas com deficiência no país, resultando na instituição de distintos hospitais, como o Hospital das Clinicas de São Paulo em 1944, nessa época existia

\footnotetext{
${ }^{2}$ FIGUEIRA, Emilio. Caminhando no silêncio: uma introdução á trajetória das pessoas com deficiência na
} história do Brasil. 3 ed. Giz Editorial. São Paulo. 2018, p.52. 
um forte vínculo entre a deficiência e a área médica ${ }^{3}$, por sua vez a sociedade pensava que como a deficiência era uma ocorrência a qual atingia apenas a pessoa possuidora da mesma, restava simplesmente providenciar-lhe alguma forma de serviço de reabilitação para pôr fim a essa questão, ou seja, havia uma associação de deficiência a doença, sendo assim aquela pessoa deveria ser internada e cuidada à distância, segregada e afastada do convívio social, em instituições especializadas, a exemplo das Santas Casas de Saúde e Misericórdias. (SASSAKI, 2010, p.29)

\section{DADOS E LEIS BRASILEIRAS SOBRE AS PESSOAS COM DEFICIÊNCIA E SUAS IMPLICAÇÕES}

Ademais o termo deficiência no Brasil em tempos pretéritos além de ser socialmente associado à incapacidade, teve também ratificação legal, uma vez que a lei no 8.742/93 em sua redação original classificava as pessoas com deficiência como aquelas incapazes de trabalhar e viver de forma independente. Mas, atualmente essa fase foi superada, pelo menos legalmente, pois a lei no 13.146 conhecida como Estatuto da Pessoa com Deficiência, uma legislação especifica que ampara as pessoas com deficiência, expondo seus direitos e deveres, e que visa abrir espaços a inclusão social destes, em seu artigo $2^{\circ}$ baseada na Convenção sobre os Direitos das Pessoas com Deficiência agora classifica tais cidadãos como:

Considera-se pessoa com deficiência aquela que tem impedimento de longo prazo de natureza física, mental, intelectual ou sensorial, o qual, em interação com uma ou mais barreiras, pode obstruir sua participação plena e efetiva na sociedade em igualdade de condições com as demais pessoas. (BRASIL, 2015, p.I)

O dispositivo em questão complementa a definição de deficiência anteriormente abordada, o mesmo deixa assim de lado o termo incapaz, isso significa uma tentativa legal de incluir essas pessoas no seio social, como já mencionado, uma análise mais apurada do mesmo permite vislumbrar a pertinente distinção entre a limitação funcional da pessoa com deficiência e a própria deficiência, pois a primeira é inerente à pluralidade humana, por sua vez a segunda resulta de imposições e barreiras postas pela sociedade.

Em vista disso, assimilar informações e dados em relação às pessoas com deficiência é de extrema relevância para a sociedade em geral, visto que a mesma necessita estruturar

\footnotetext{
${ }^{3}$ Brasil, Ministério da Saúde. História e evolução dos hospitais. Rio de janeiro, 1965. Disponível em < http://bvsms.saude.gov.br/bvs/publicacoes/cd04_08.pdf >. Acesso em: 7 de julho de 2018, p.64.
} 
seus ambientes para melhor recepcionar tais pessoas proporcionando assim uma melhor acessibilidade. Além disso, as pesquisas em torno das pessoas com necessidades especiais despontaram de um modo geral a parir de 1970, tal fato é atribuído às mobilizações realizadas pelos grupos que apoiavam a causa de uma maior incorporação social dessas pessoas.

Existem distintos momentos históricos internacionais que marcam o início dessa trajetória pode-se trazer à baila o ano de 198ı quando a Organização das Nações Unidas (ONU) proclamou o mesmo como o Ano Internacional das Pessoas Portadoras de Deficiência, tendo como principal resultado a proposta do Programa de Ação Mundial para Pessoas com Deficiência posteriormente adotada em 1982 pela Assembleia Geral da Organização das Nações Unidas. (LENZI, 2012, p.2). Como já demostrado previamente a percepção acerca das pessoas com deficiência vem se transformado ao decorrer do tempo, da mesma forma isso ocorre com as noções que divulgam as proporções da deficiência. Uma maneira de observar essa evolução é por meio dos recenciamentos demográficos. Nos censos brasileiros gerais de 1872 , I900 e de 1920 apenas considerou-se as deficiências sensoriais, a saber, os cegos e surdos-mudos (como na ocasião eram conhecidos) como demostra a Tabela I, a mesma deve ser interpretada da seguinte forma, a quantidade de cegos ou surdos-mudos para cada dez mil habitantes homens ou mulheres. (CANTORANI, et al, 2015)

Tabela I - Incidência de deficiência em número absoluto por Io.ooo habitantes entre homens e mulheres.

\begin{tabular}{llllllc}
\hline \multicolumn{2}{l}{ Anos } & \multicolumn{2}{l}{ Cegos } & \multicolumn{3}{c}{ Surdos-Mudos } \\
\hline & Homens & Mulheres & Total & Homens & Mulheres & Total \\
\hline 1872 & 9,469 & 6,379 & 15,848 & 7,157 & 4,438 & 11,595 \\
\hline 1900 & 10,250 & 8,563 & 18,813 & 4,224 & 3,137 & 7,361 \\
\hline 1920 & 16,113 & 13,761 & 29,874 & 14,525 & 11,689 & 26,214 \\
\hline
\end{tabular}

Fonte: Revista Brasileira de Educação Especial (http://www.scielo.br/scielo.php? script $=$ sci_arttext\&pid $=$ Si413-65382015000100159\#B04)

Nessa época o que se levou em conta foi simplesmente a intenção de fazer o quantitativo de deficientes sensoriais, o foco estava justamente na limitação física e não na tentativa de integrar tais pessoas, o censo demográfico de 1940, seguiu os moldes dos censos anteriores mencionados. No decorrer dos anos, outros censos demográficos foram realizados e cada vez mais os mesmos passaram a ser aprimorados ganhando mais detalhes, pode-se trazer à baila os censos dos anos de 1991, 2000 e 2010. 


\section{I Um enfoque na proposta de mercado de trabalho inclusivo no ano de 1991}

O censo demográfico de 1991, em virtude da lei no 7.853 de 24 de outubro de 1989, foi objetivo nas suas investigações, porque a lei supracitada determina que as pessoas que tem deficiência sejam incluídas impreterivelmente nos censos demográficos nacionais sendo abordadas de formas especificas. Este apurou que existiam nesse ano 1,7 milhões de pessoas com deficiência no país, sendo que somente foram levadas em consideração as deficiências que na época eram consideradas graves segundo Cantorani e outros (2015), como mostra a figura I a seguir:

Figura I- Distribuição das deficiências em 1991 a partir do Censo

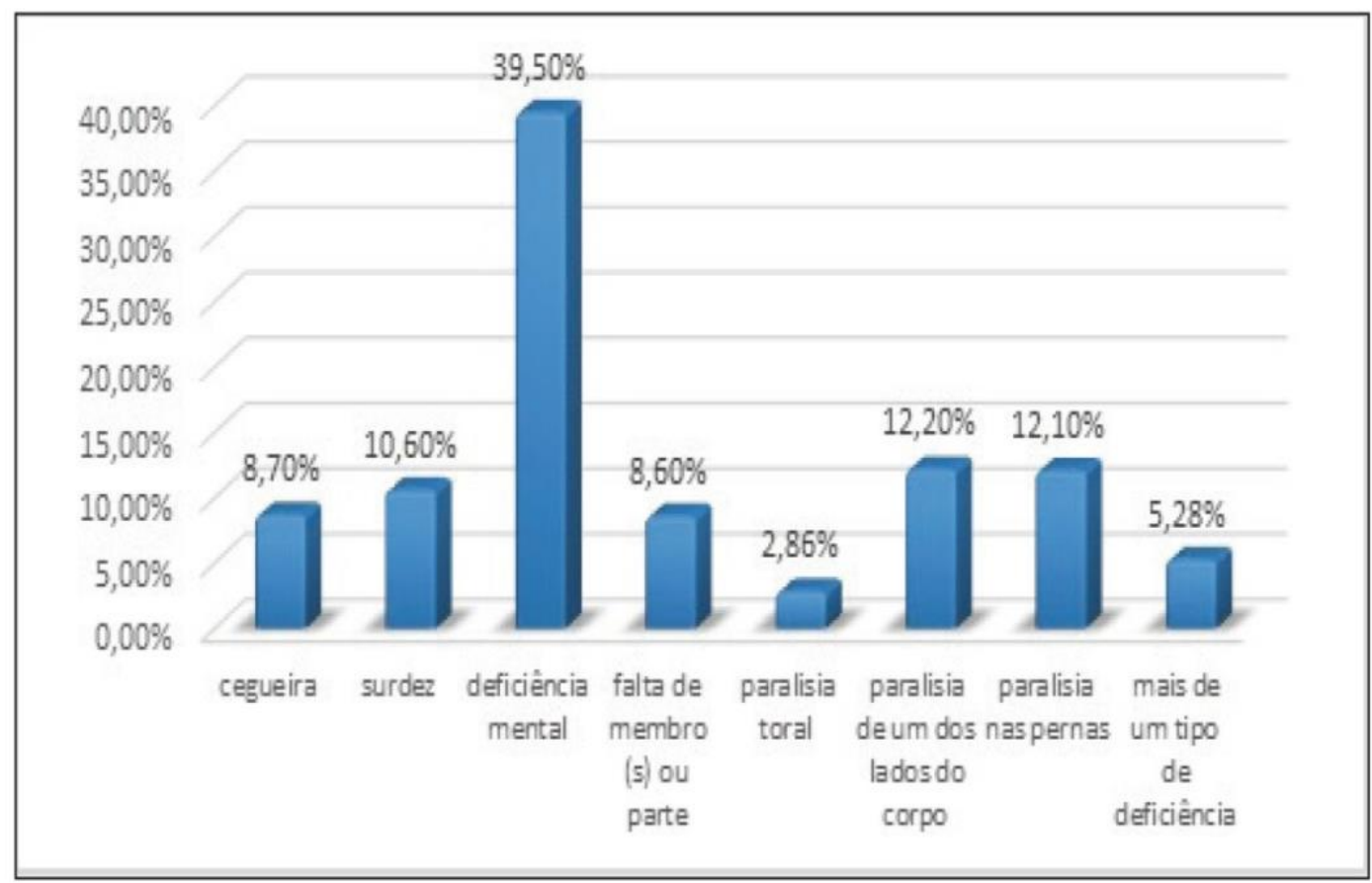

Fonte: Revista Brasileira de Educação Especial (http://www.scielo.br/scielo. php? script=sci_arttext\&pid=S1413-6538201500o100159\#Bo4)

Ademais esse ano também foi marcado com a promulgação da lei no 8.213 de 24 de julho de I991, conhecida como Lei de Cotas, a qual estabelece e regulamenta a contratação de pessoas com deficiência nas empresas. Segundo o artigo $93^{\circ}$ da mesma as empresas que possuírem o quadro com cem ou mais funcionários devem reservar de $2 \%$ a $5 \%$ de seus cargos com beneficiários reabilitados ou com pessoas com deficiência, devendo ser observada a seguintes proporções, até 200 empregados a reserva deve ser de $2 \%$, de 201 a 500 empregados 
a reserva é de $3 \%$, por sua vez de 500 a iooo empregados a reserva é de $4 \%$, e por último de Ioor em diante a reserva é de 5\%. (BRASIL, I991, p.34)

No recenseamento demográfico de I99I a partir das pesquisas realizadas, foi aferido que $85 \%$ das pessoas com deficiência entrevistadas não trabalharam nos últimos doze meses anteriores ao censo, entre aquelas que trabalharam $95 \%$ foi de forma eventual e somente $5 \%$ foram empregados de forma habitual. Dessa forma o trabalho habitual corresponde 13,4\% das pessoas com deficiência, por sua vez na população total ele representa 36,8\% (CHAGAS \& VIOTTI, 2003, p.24). A partir dessa análise percebe-se que antes da promulgação da lei supracitada a inserção das pessoas com deficiência no mercado de trabalho era restrito, por causa de distintos fatores como a escassez de uma educação inclusiva, seja pela falta de incentivo de capacitação profissional destas pessoas, ou pelo fato desses locais não estarem com seus ambientes estruturados para recebê-las por falta de empresas inclusivas, apesar desses fatores negativos este fato foi se modificando vagarosamente ao longo dos anos. É valido colocar que a inclusão de tais pessoas é de extrema relevância no processo de socialização das mesmas, por conta disso o Ministério do Trabalho através de seus agentes está fortalecendo o sistema de fiscalização nas empresas, buscando proporcionar o cumprimento da Lei de Cotas e assim possibilita que esse público possa participar de forma mais ativa de atividades essências a manutenção de sua dignidade humana. (Simonelli \& Filho, 2017, p.862)

\subsection{Censo demográfico de 2000 e a instituição legal da acessibilidade}

Por sua vez o censo demográfico do ano 2000 apresentou um grande avanço na aquisição de dados sobre as pessoas com necessidades especiais, pois o mesmo não se deteve apenas na deficiência em si, este trouxe para o centro das pesquisas a definição de limitações de atividades, com o escopo de associar à deficiência a aptidão de execução. Além disso, o conceito de base foi adotado em virtude das orientações internacionais, "especialmente com a International Classification of Functioning Disability and Health ICF (200I) elaborada e difundida pela Organização Mundial da Saúde - OMS” (CANTORANI et al, 2015), e ainda pode-se colocar que:

A ampliação do conceito de base para a pesquisa das deficiências no Censo 2000 permitiu um aumento vultuoso do número de pessoas que se declararam com alguma deficiência. Para uma população de 169.872 .856 pessoas, 24.600 .256 pessoas se declararam com algum tipo de deficiência, o que corresponde à $14,3 \%$ da população em 200o. A distribuição da população com deficiência, segundo o tipo da deficiência e grau de severidade. (CANTORANI, et al, 2015) 
A partir desse censo, fica notório que quando é adotado o método que leva em conta os impedimentos e não somente as incapacidades amplas ocorrem à elevação dos números daqueles que se declaram deficientes como consta na tabela 2 a seguir:

Tabela 2 - População por tipo de deficiência segundo sexo.

\begin{tabular}{|c|c|c|c|c|}
\hline & \multirow[t]{2}{*}{ Tipo de deficiência } & \multicolumn{2}{|c|}{ Total Homens } & Mulheres \\
\hline & & II 420544 & & 13179712 \\
\hline \multicolumn{2}{|c|}{ Deficiência mental permanente 2844937} & I 545462 & & I 299474 \\
\hline Deficiência física & I 416 o6o & 861196 & & 554864 \\
\hline \multirow{3}{*}{ Deficiência visual } & Incapaz de enxergar & 148023 & 70160 & 77863 \\
\hline & Grande dificuldade permanente de enxergar & 2435873 & I 044746 & 1 I 391 I27 \\
\hline & Alguma dificuldade permanente de enxergar & 14060946 & 6 6I44 I68 & 79916778 \\
\hline \multirow{3}{*}{ Deficiência auditiva } & Incapaz de ouvir & 166365 & 86431 & 799934 \\
\hline & Grande dificuldade permanente de ouvir & 883079 & 466043 & $4 \quad 417037$ \\
\hline & Alguma dificuldade permanente de ouvir & 4685655 & 2465745 & 22219910 \\
\hline \multirow{4}{*}{ Deficiência motora } & Incapaz de caminhar ou subir escada & 574 I86 & 275301 & 298885 \\
\hline & Grande dificuldade permanente de caminhar ou subir escada & 1772690 & 739219 & 1033471 \\
\hline & Alguma dificuldade permanente de caminhar ou subir escada & 15592908 & 2280551 & 3312357 \\
\hline & Nenhuma destas deficiências & \multicolumn{2}{|c|}{143726947 71 391 433} & 72335514 \\
\hline
\end{tabular}

Fonte: Revista Brasileira de Educação Especial (http://www.scielo.br/scielo.php? script $=$ sci_arttext $\&$ pid $=$ Si413-65382015000100159\#Bo4)

De forma geral o censo em questão foi um marco, sendo que trouxe definições mais minuciosas sobre a deficiência no país, "com este novo encaminhamento, tanto o indicativo de "alguma dificuldade", quanto o indicativo de "grande dificuldade", seja para a condição de enxergar, de ouvir ou para a condição da mobilidade, passam a estabelecer uma visão mais clara da dimensão da deficiência" (CANTORANI, et al, 2015). Nele é possível captar uma maior sentimentalidade em relação à deficiência, tendo em vista que aborda aspectos que ampliam a visão a respeito da mesma como se pode perceber na tabela acima.

Neste mesmo ano o Diário Oficial da União publicou a lei no 10.098 de 19 de dezembro de 2000, conhecida popularmente como Lei da acessibilidade, em suma esta tem como escopo a promoção da erradicação de barreiras e obstáculos que dificultem a locomoção das pessoas com deficiência ou com mobilidade reduzida. A mesma traz noções fundamentais para compreender melhor os pormenores desse assunto, um conceito que compete aqui ser citado para endossar a discussão é justamente o termo acessibilidade:

Acessibilidade: possibilidade e condição de alcance para utilização, com segurança e autonomia, dos espaços, mobiliários e equipamentos urbanos, das edificações, dos 
transportes e dos sistemas e meios de comunicação, por pessoa portadora de deficiência ou com mobilidade reduzida. (BRASIL, 200o, p.I)

Ademais cabe pontuar que a realização da acessibilidade é uma antiga reinvindicação dos movimentos das pessoas com deficiência. Visando atender esse anseio o Governo lançou, após quatro anos de vigor da lei supracitada, o Programa Brasileiro de Acessibilidade Urbana- Brasil Acessível, tal projeto tem como escopo impulsionar os prefeitos e governadores a construírem cidades e estados mais acessíveis a pessoas com deficiência (BRASIL, 2004).

Apesar desse impulso governamental em promover um país mais inclusivo, no ano de 2000 não se verificou o desenvolvimento esperado no meio urbano, com o avanço do tempo surgiram outras leis que versam sobre este assunto, nos dias hodiernos existem pelo menos cinquenta e três dispositivos que versam sobre o tema acessibilidade entre leis, decretos e resoluções ${ }^{4}$, fazendo uma breve contextualização constata-se que na realidade brasileira o que predomina são calçadas públicas em péssimas condições de mobilidade, prédios públicos sem rampa de acesso, transportes públicos sem elevadores especializados e quando possuem muitos estão danificados, falta de elevadores em lugares específicos, ausência de sinalização tátil, entre outros instrumentos essenciais a mobilidade e acessibilidade de tais pessoas.

\subsection{Educação inclusiva: uma aliada no processo de socialização das pessoas com deficiência}

O Instituto Brasileiro de Geografia e Estatística (IBGE) foi o órgão responsável pela realização do censo demográfico de 2010 , bem como pela execução dos dois últimos recenciamentos supracitados, o mesmo através de seus dados estimou que a população brasileira tem em torno de 190.732.694 pessoas, no meio destas aproximadamente 4,6 milhões de pessoas revelaram possuir algum tipo de deficiência o que corresponde aproximadamente $24 \%$ da população total do país, o censo levou em consideração as deficiências consideradas permanentes, a saber, a visual, a motora, auditiva e mental ou intelectual (BRASIL, 2oro, p.ir4). Como pode se observar na figura 2:

\footnotetext{
${ }^{4}$ Brasil. Coordenadoria Nacional para Integração da Pessoa Portadora de Deficiência. Acessibilidade -Brasília: Secretaria Especial dos Direitos Humanos, 2008.
} 
Figuras 2- Deficientes no Brasil

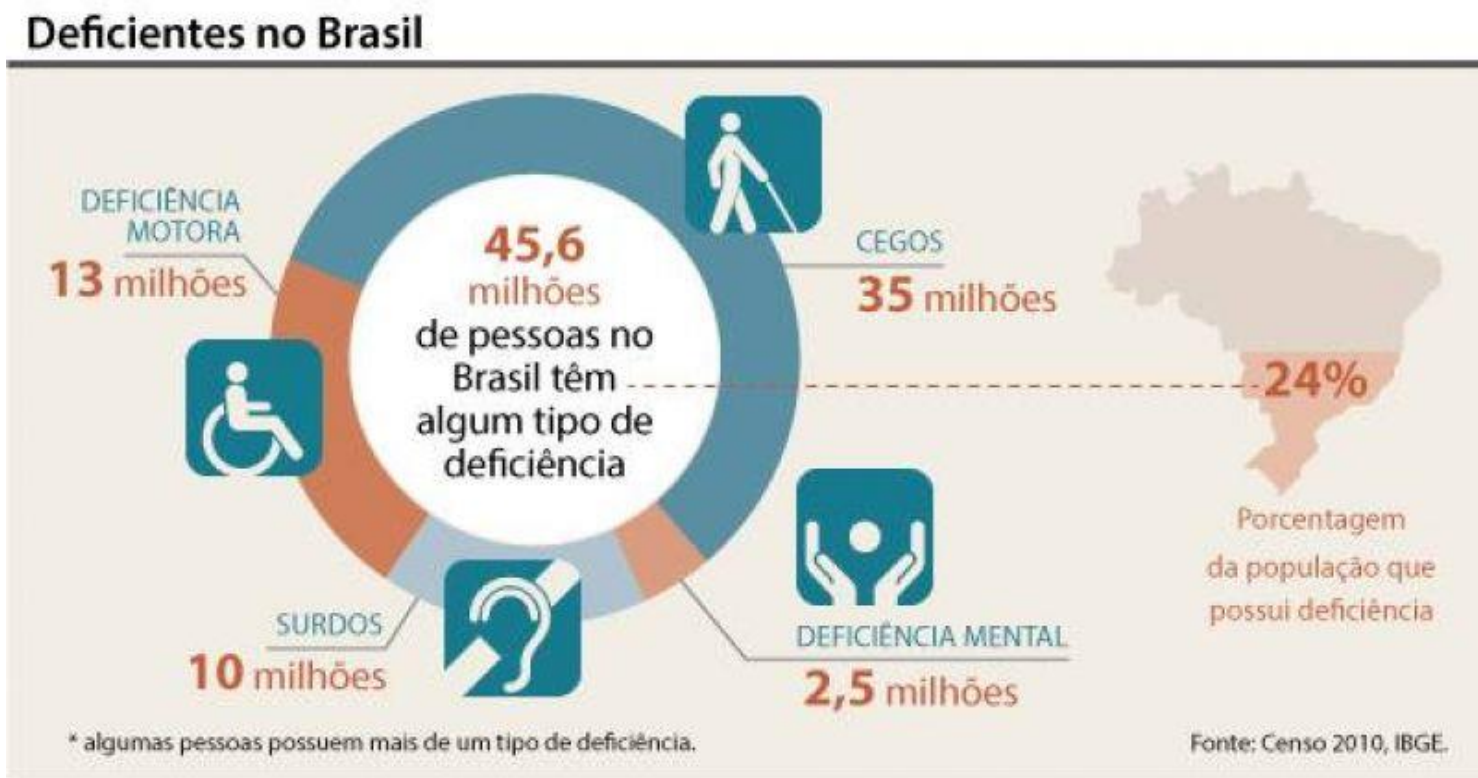

Fonte: http://www2.camara.leg.br/camaranoticias/imagens/imgNoticiaUploadi464616115916.jpg

Constatou-se que a deficiência com maior representatividade é a visual com cerca de 35 milhões de pessoas, para chegar a tal resultado foi questionado aos entrevistados a dificuldade permanente de enxergar, avaliando-os com o uso de óculos ou lente. A segunda deficiência que mais se verificou no país foi à motora com aproximadamente 13 milhões de pessoas o método realizado para obter dados suficientes foi à pesquisa contendo a seguinte indagação, se a pessoa tem dificuldade permanente de caminhar ou subir escadas, para avaliação utilizaram-se instrumentos como prótese, bengala entre outros. A deficiência auditiva ficou em terceiro lugar no ranking das deficiências mais verificadas no país com cerca de ro milhões de pessoas, a pesquisa investigou se os entrevistados tinha dificuldade permanente de ouvir, sendo avaliada com o uso de aparelho auditivo, na situação da pessoa utilizá-lo.

Em última posição ficou a deficiência mental ou intelectual com aproximadamente 2,5 milhões de pessoas, essa averiguação levou em conta se as pessoas possuíam alguma deficiência mental ou intelectual, a mesma deve ser permanente, e ainda deve provocar limitações nas atividades habituais a exemplo de estudar ou trabalhar, sendo que em todas 
as pesquisas foram consideradas as seguintes classificações: não consegue de modo algum, grande dificuldade, alguma dificuldade e nenhuma dificuldade. (BRASIL, 2010, p. 27, 28)

Mediante a todas essas informações infere-se que o censo em foco abordou de forma mais pormenorizada as deficiências mais registradas no país por meio de seu grau de severidade, com isso possibilitando estimar quais pessoas realmente necessitam ser incluídas nas políticas públicas oferecidas pelo governo. Ainda cabe colocar um dado importante trazido por esse censo que diz respeito ao nível de instrução das pessoas com deficiência. $O$ grau de instrução é verificado para as pessoas acima de quinze anos ou mais de idade e seus respectivos níveis de escolaridade.

No ano de 2010 entre as pessoas que se declaram possuir algum tipo de deficiência I4,2\% possuíam o fundamental completo, $17,7 \%$, o médio completo e 6,7\% possuíam superior completo, a dimensão definida como "não determinada" foi igual a o,4\%. Neste mesmo ano ainda foi verificado que uma parcela considerável da população com deficiência não possuía níveis de instrução cerca de 61,1\% e também não tinha conseguido concluir o ensino fundamental. (CARTILHA DO CENSO 2010, 2012, p.17)

Com o objetivo de reverter esses baixos níveis de escolaridade são tomadas uma série de medidas pelo governo para promover uma maior inclusão escolar dos alunos com deficiência, mediante isso é aprovada pelo Conselho Nacional de Educação- CNE a Resolução CNE/CEB nº4/2010, a qual estabelece Diretrizes Curriculares Nacionais da Educação Básica e recomenda em seu artigo $29^{\circ}$ que as instituições de ensino devem matricular os estudantes com deficiência, transtornos globais do desenvolvimento e altas habilidades/superdotação nas classes comuns do ensino regular e no Atendimento Educacional Especializado - AEE. É promulgado também o Decreto n ${ }^{\circ} 7084 / 2010$, este dispõe sobre os programas nacionais de materiais didáticos, o mesmo pontua em seu artigo $28^{\circ}$ que Ministério da Educação deverá adotar instrumentos para promoção da acessibilidade nos programas de material didático destinado aos estudantes da educação especial e de seus professores das escolas de educação básica públicas.

Além disso, visando proporcionar políticas públicas de inclusão social das pessoas com deficiência é, aprovado um ano após o censo, o Decreto $n^{\circ} 7612 / 2011$ que institui o Plano Nacional dos Direitos da Pessoa com Deficiência - Viver sem Limite, visando estimular por 
meio da integração e articulação de políticas, programas e ações, o exercício pleno e equitativo dos direitos das pessoas com deficiência. (MEC $\backslash$ SECADI, 20I4, p.6)

Além disso, se pode colocar que a educação inclusiva é extremamente importante tanto para os alunos com deficiência quanto para aqueles sem deficiência, entretanto a mesma ao longo dos anos depara-se com distintas barreiras para sua implantação, como preconceito, falta de capacitação profissional e escassa estrutura adequada nas escolas públicas, as quais lentamente estão sendo superadas. Ademais, é preciso colocar primeiramente que um ambiente escolar inclusivo gera aos discentes com alguma deficiência benefícios acadêmicos, como melhores rendimentos em seu aprendizado, impulsos para progredir em seus estudos concluído o ensino fundamental e médio e aumentando a propensão para o ingresso no ensino superior, entre outros, dentre os benefícios sociais da mesma destacam-se a conquista de um grupo social no qual as pessoas com deficiência podem interagir, a propensão maior para conquistar um emprego e assim alcançar mais rapidamente sua independência.

Já as pessoas sem deficiência que estudam em escolas inclusivas desenvolvem uma maior receptividade para as diferenças, tornando assim pessoas menos preconceituosas, embora muitas observações indiquem que um aluno com deficiência atrapalha no aprendizado dos demais, estudos apontam que as influências sobre alunos sem deficiência que são ensinados em uma sala de aula inclusiva são neutras ou positivas, desse modo inferese que uma educação inclusiva promove expressos benefícios sociais. (INSTITUTO ALANA, 2016, p. 7,13, 14,15)

\section{CONSIDERAÇÕES FINAIS}

Portanto as pessoas com deficiência no decorrer dos séculos sempre foram vistas por um viés desfavorável, as mesmas já passaram por associações a termos depreciativos como maldição, incapazes, doentes, inferiores, entre outros, essas expressões citadas demostram a marginalização, preconceito e impugnação da sociedade por essas pessoas, esta predisposição a exclusão dos considerados como diferentes pode ser explicada por uma perspectiva cultural, pois como Tylor elucida os costumes, crenças, hábitos, entre outros caracteres culturais, são assimilados pelo indivíduo que pertence a uma sociedade, mediante isso para romper com essa tradição de preconceito, se faz necessário ocorrer uma mudança gradativa 
de conceitos, paradigmas e padrões sociais com o escopo que a população brasileira consiga superar esse negativo histórico que cerca as pessoas com deficiência, isso tudo somente poderá ser efetivado por meio da ampliação de discussões sobre o tema, a construção de debates públicos, a publicação de obras cientificas que versem sobre esse tema, são fundamentais para fomentar a inclusão social destes.

O termo deficiência por ser complexo esteve em evolução constante durante os anos, a legislação brasileira esteve sujeita a essas mudanças, dado que em um primeiro momento as pessoas com deficiência foram tratadas legalmente como seres incompletos dotados de subalternidade intrínseca, por outro lado, os legisladores começaram a compreender a deficiência por uma perspectiva mais humanizada, logo esta passou a ser enxergada como uma limitação física, os mesmos entenderam que as pessoas com deficiência não são um problema a sociedade, pois a deficiência resulta das barreiras estruturais e sociais imposta pela população brasileira, assim estes construtores das normas brasileiras pontuam que a deficiência é algo externo.

Dessa forma quando os setores sociais se estruturam as pessoas com deficiência conseguem superar seus limites, dito isto o mercado de trabalho composto por empresas, fabricas, repartições públicas, entre outras localidades, precisam também se tornar integralizador, possibilitando que tais trabalhadores demonstrem as suas múltiplas habilidades profissionais. Por isto, que a acessibilidade é de extrema importância para a mobilidade das pessoas com deficiência, as mesmas anseiam poder desfrutar plenamente do seu direito de ir e vir com total segurança, o que na realidade brasileira, apesar dos esforços governamentais, não está sendo permitido, na verdade falta uma cobrança maior da sociedade para mudanças estruturais urbanas, precisa também acontecer à ampliação da representatividade das pessoas com necessidades especiais no Congresso Nacional, já existem representantes com deficiência na política brasileira, mas o número ainda é pequeno, visto os dados do Censo de 2010 que aponta que $24 \%$ da população tem algum tipo de deficiência, essa representatividade sem sombras de dúvida necessita crescer consideravelmente para fortalecer e endossar a luta pelo cumprimento dos direitos já estabelecidos e os que faltam ser conquistados, é preciso continuar colocando que o apoio da sociedade para essas mudanças é indispensável, se faz necessário uma comunhão entre as pessoas com e sem deficiência. 
Ademais o avanço das pesquisas, a preocupação do governo em mapear da melhor forma possível as pessoas com deficiência, para inclui-las em suas políticas públicas, resultou na construção de uma legislação composta por decretos, leis, resoluções e normas que versam sobre a necessidade de acolher tais pessoas, um mecanismo utilizado é justamente a educação inclusiva. Faz-se preciso colocar que a educação é um instrumento que transpassa o anseio de uma carreira profissional, e atinge um amplo campo da socialização, educar não é somente transferir conhecimentos escolares que ajudam a compreender as formas do universo, mas, é também tirar o indivíduo de um isolamento inicial e incluí-lo em um círculo de relações sejam com colegas, professores ou com os funcionários destes espaços, a educação inclusiva visa resgatar os alunos com deficiência que estão segregados, distanciando deste convívio socializador e incorporara-los neste contexto. Mas, assim como a acessibilidade a educação inclusiva no país, está também a mercê das barreiras estruturais, sociais, e financeiras impostas.

Pois é nítido que nas escolas públicas, onde a maior parte dos brasileiros com e sem deficiência estudam, a estrutura oferecida dificulta o acesso aos alunos com necessidades especiais, além disso, a falta de capacitação profissional por distintos fatores é nítida, o governo apesar de expor que investe muito na educação pública brasileira está longe de oferecer uma educação de qualidade para a população em geral. Dito isso é necessário sim, um maior investimento do governo para que a educação inclusiva possa ocorrer com êxito, os profissionais da educação precisam ser capacitados através de cursos, orientações e incentivos para melhor receber discentes com deficiência, as escolas necessitam ser estruturadas adequadamente para solucionar esse déficit nessa modalidade de educação, além disso, é de extrema urgência que o Estado transfira mais investimento para este setor, em vista de que a educação inclusiva é capaz de mudar exponencialmente a trajetória das pessoas com deficiência no país.

\section{REFERÊNCIAS}

BRASIL. Coordenadoria Nacional para Integração da Pessoa Portadora de Deficiência. Acessibilidade -- Brasília: Secretaria Especial dos Direitos Humanos, 2008.

BRASIL. Decreto Lei no $3298 \backslash 99$ 20 de Dezembro de 1999. Regulamenta a Lei $n^{\circ} 7.853$, de 24 de outubro de 1989, dispõe sobre a Política Nacional para a Integração da Pessoa Portadora de Deficiência, consolida as normas de proteção, e dá outras providências. Diário Oficial da União. Disponível em < http://www.planalto.gov.br/ccivil_03/decreto/d3298.htm>. Acesso: Io de julho de 202I. 
BRASIL, Instituto Brasileiro de Geografia e Estatística (IBGE). Censo Demográfico 200o: características gerais da população. Disponível em: 〈https://ww2.ibge.gov.br/home/estatistica/populacao/censo20oo/populacao/censo20oo_p opulacao.pdf $>$. Acesso em: 22 de junho de 2021.

BRASIL. Instituto Brasileiro de Geografia e Estatística(IBGE). Censo Demográfico, 2oı: características gerais da população, religião e pessoas com deficiência. Disponível em:< https://biblioteca.ibge.gov.br/visualizacao/periodicos/94/cd_201o_religiao_deficiencia.pdf >. Acesso em: 23 de junho de 2021.

BRASIL. Lei no 8.213 de 24 de julho de 199r. Dispõe sobre os planos de benefícios da Previdência Social e dá outras providências. Diário Oficial da União. Disponível em:< http://ftp.medicina.ufmg.br/osat/legislacao/Lei_8213_MPAS_22092014.pdf >. Acesso em: 22 de julho de 202I.

BRASIL. Lei no $\mathbf{1 0 . 0 9 8}$, de 19 de dezembro de 2000. Estabelece normas gerais e critérios básicos para a promoção da acessibilidade das pessoas portadoras de deficiência ou com mobilidade reduzida, e dá outras providências. Diário Oficial da União. Disponível em: < http://portal.mec.gov.br/arquivos/pdf/leiroo98.pdf>. Acesso em: 24 de junho de 202I.

BRASIL. Lei no 13.146 de 6 de julho de 2015. Institui a Lei Brasileira de Inclusão da Pessoa com Deficiência (Estatuto da Pessoa com Deficiência). Diário Oficial da União. Disponível em: $\langle$ http://www.punf.uff.br/inclusao/images/leis/lei_13146.pdf $\rangle$. Acesso em: 9 de julho de 202I.

BRASIL. Ministério da Educação-MEC \Secretaria de Educação Continuada, Alfabetização, Diversidade e Inclusão-SECADI. Política Nacional de Educação Especial na Perspectiva da Educação Inclusiva. Disponível em: < http://portal.mec.gov.br/docman/dezembro-2or4$\mathrm{pdf} / \mathrm{I} 6690$-politica-nacional-de-educacao-especial-na-perspectiva-da-educacao-inclusiva05122014>. Acesso em: 22 de julho de 2021.

BRASIL. Ministério da Saúde. História e evolução dos hospitais. Rio de janeiro, 1965. Disponível em: < http://bvsms.saude.gov.br/bvs/publicacoes/cdo4_o8.pdf >. Acesso em: 7 de junho de 202I.

BRASIL. Programa Brasileiro de Acessibilidade Urbana- Brasil Acessível. Caderno 2: construindo a cidade acessível. 2004. Disponível em: < http://www.iparadigma.com.br/bibliotecavirtual/items/show/I20 >. Acesso em: 2I de julho de 2021.

CANTORANI, José Roberto Herrera; VARGAS, Leandro Martinez; REDKVA, Paulo Eduardo; PILATTI, Luiz Alberto \& GUTIERREZ, Gustavo Luis. A Dimensão da Deficiência e o Olhar a Respeito das Pessoas com Deficiência a Partir dos Recenseamentos no Brasil. Revista Brasileira de Educação Especial vol.21 no.I. ISSN 1980-5470. Marília Jan./Mar. 2015. Disponível em:< http://www.scielo.br/scielo.php?script=sci_arttext\&pid=SI413-6538201500o100159>. Acesso em: 22 de julho de 2021.

CARTILHA DO CENSO 2010. Pessoas com Deficiência / Luiza Maria Borges Oliveira / Secretaria de Direitos Humanos da Presidência da República (SDH/PR) / Secretaria Nacional de Promoção dos Direitos da Pessoa com Deficiência (SNPD) / CoordenaçãoGeral do Sistema de Informações sobre a Pessoa com Deficiência; Brasília: SDH- 
PR/SNPD, 2012. Disponível em: http://www.portalinclusivo.ce.gov.br/phocadownload/cartilhasdeficiente/cartilha-censo2010-pessoas-com-deficiencia.pdf $>$. Acesso em: I2 de junho de 2021.

CHAGAS, Ana Maria de Resende \& VIOTTI, Renato Baumgratz. Retrato da pessoa com deficiência no Brasil segundo o censo de 1991. ISSN 1415-4765. Texto para discussão no 975 . Disponível: < http://www.ipea.gov.br/portal/images/stories/PDFs/TDs/td_0975.pdf>. Acesso em: 23 de julho de 2021.

CONVENÇÃO SOBRE OS DIREITOS DAS PESSOAS COM DEFICIÊNCIA: Protocolo Facultativo à Convenção sobre os Direitos das Pessoas com Deficiência: Decreto Legislativo no 186 , de o9 de julho de 2008: Decreto no 6.949, de 25 de agosto de 2009. $4^{\underline{a}}$ Ed., rev. e atual. Brasília: Secretaria de Direitos Humanos, 20I0. Ioop, p.23-I4. Disponível em< http://www.pessoacomdeficiencia.gov.br/app/sites/default/files/publicacoes/convencao pessoascomdeficiencia.pdf $>$. Acesso em ro de julho de 2021.

\section{DEFICIENTES}

<http://www2.camara.leg.br/camaranoticias/imagens/imgNoticiaUploadi464616115916.jpg >. Acesso em: 8 de julho de 202I.

DISTRIBUIÇÃO DAS DEFICIÊNCIAS EM 199ı A PARTIR DO CENSO. Revista Brasileira de Educação Especial vol.2i no.I. ISSN 1980-5470. Marília Jan./Mar. 2015. Disponível em:< http://www.scielo.br/scielo.php?script=sci_arttext\&pid=SI4I36538201500oroor59\#Bo4>. Acesso em: 22 de julho de 2021.

FIGUEIRA, Emilio. Caminhando no silêncio: uma introdução á trajetória das pessoas com

deficiência na história do Brasil. 3 ed. Giz. Editorial. São Paulo. 2018.

INCIDÊNCIA DE DEFICIÊNCIA EM NÚMERO ABSOLUTO POR 10.000 HABITANTES ENTRE HOMENS E MULHERES. Revista Brasileira de Educação Especial vol.21 no.I. ISSN 1980-5470. Marília Jan./Mar. 2015. Disponível em:< http://www.scielo.br/scielo.php?script=sci_arttext\&pid=SI413-65382015000100159\#Bo4>.

Acesso em: 22 de julho de 2021.

INSTITUTO ALANA. Os Benefícios da Educação Inclusiva para estudantes com e sem deficiência. Disponível em: <https://alana.org.br/wpcontent/uploads/2016/II/Os_Beneficios_da_Ed_Inclusiva_final.pdf_ $>$. Acesso em: 22 de julho de 202I.

LARAIA, Roque de Barros. Cultura: um conceito antropológico. ig ed. Rio de Janeiro: Jorge Zahar, 2006.

LENZI, Maíra Bonna. Os dados sobre Deficiência nos Censos Demográficos Brasileiro. Disponível em:<www.abep.org.br/publicacoes/index. php/anais/article/download/204I/r999>. Acesso em: 22 de julho de 202I.

POPULAÇÃO POR TIPO DE DEFICIÊNCIA SEGUNDO SEXO. Revista Brasileira de Educação Especial vol.2i no.I. ISSN 1980-5470. Marília Jan./Mar. 2015. Disponível em:< http://www.scielo.br/scielo.php?script=sci_arttext\&pid=SI413-6538201500o100159\#Bo4>.

Acesso em: 22 de julho de 202I.

SASSAKI, Romeu Kazuma. Inclusão: construindo uma sociedade para todos. $8 \mathrm{ed}$. Rio de Janeiro. WVA. 2010,18op. 
SILVA, Luciene M. da. O estranhamento causado pela deficiência: preconceito e experiência. Revista Brasileira de Educação v. II n. 33 set./dez. 2006. Disponível em:< http://www.scielo.br/pdf/\%oD/rbedu/virn33/a04VII33.pdf >. Acesso em: Io de julho de 2021.

SIMONELLI, Angela Paula \& Filho, José Marçal Jackson. Análise da inclusão de pessoas com deficiência no trabalho após 25 anos da lei de cotas: uma revisão da literatura. Cad. Bras. Ter. Ocup. São Carlos, v. 25, n. 4, p. 855-867, 2017. ISSN 2526-8910. Disponível: < http://www.cadernosdeterapiaocupacional.ufscar.br/index.php/cadernos/article/view/ı8 42/920>. Acesso em: 22 de julho de 202I. 